\title{
BEST VALUE PROCUREMENT FROM A CONTRACTOR POINT OF VIEW
}

\author{
Emilie Sofie Lesjø ${ }^{1}$, Paulos Abebe Wondimu², Ola Lædre ${ }^{3}$
}

\begin{abstract}
Best Value Procurement (BVP) was introduced in Norway in 2016. Since then, more than ten pilot projects have tested the method. So far, limited research has been carried out to explore the contractors' experiences on BVP to improve the method for future projects. The purpose of this paper is to fill part of this research gap by exploring a contractor's experiences from several projects using the method. By looking at five road projects that have tested out the BVP method, a trend can be seen in how the evaluation of the offers was conducted. Data was collected from five pilot road projects through three in-depth interviews with key persons and a document study. The results show how the evaluation of the price aspect has changed over time. In three of the five projects, a formula was used that urged the contractors to set prices low in order to score additional points. This formula gained criticism from both the contractors and the BVP experts hired to help the contractors. BVP has contributed, to a certain extent, to Lean implementation. However, the practice should be improved to increase value and transparency and minimize conflict and waste.
\end{abstract}

\section{KEYWORDS}

Best value procurement, BVP, lean construction, value, early contractor involvement, ECI

\section{INTRODUCTION}

Best Value Procurement was created by Dean Kashiwagi at Arizona State University. The method urges the client to look for the best value at the lowest cost. Contractors must prove that they can deliver with regard to the project objectives and that they understand the risks and will implement actions to mitigate the risks (Kashiwagi et al. 2012).

The construction industry is accountable for 16\% of the GDP (Gross domestic product) in Norway, the largest measured percentage to date (Brekkhus 2017). GDP is an indicator for the gross value added in a country over a certain period of time, often

1 M.Sc. Student, Department of Civil and Environmental Engineering, Norwegian University of Science and Technology (NTNU), +47 94383 498, emilie.lesjo@gmail.com

2 Researcher, Department of Civil and Environmental Engineering (DCEE), Norwegian University of Science and Technology (NTNU), Trondheim, Norway/Senior Engineer, Norwegian Public Roads Administration, Norway, +47 90111 814, paulos.wondimu@ntnu.no/paulos.wondimu@ vegvesen.no

3 Associate Professor, DCEE, NTNU, ola.ladre@ntnu.no 
annually (Focus Economics 2018). Changes concerning productivity in this sector will, therefore, have significant impact on the Norwegian economy. Best Value Procurement (BVP) aims to streamline the procurement phase and thus increase total productivity in the construction industry (Difi 2016).

BVP was introduced in Norway in 2016. Since then, more than ten pilot projects have been started with the goal of finding out whether the method creates higher value and decreases costs and use of resources in Norway. The pilot projects were initiated by the Norwegian Directory of Procurement and ICT, called Difi (Direktoratet for forvaltning og IKT). The pilot projects vary from mega-infrastructure projects to kindergartens. So far, limited research has been carried out to explore the contractors' experiences with BVP and to improve the method for future projects. This paper fills part of this research gap by addressing the following research questions:

- How was BVP implemented in practice?

- What were the contractors' experiences with the BVP method?

- How can the method be improved in the future?

This study has some limitations. First, the study is based on only five case studies and all of them are infrastructure projects conducted by the same client. Second, experiences from only one contractor are explored. Third, the study is based on the primary contractor's experiences with BVP, but it was not extended to explore the experiences of sub-contractors. Fourth, all cases are ongoing projects at different phases. Since the projects still in progress, the results are not final.

A theoretical background is presented where the BVP process is described. Furthermore, results from document study and interviews will be presented along with a discussion. Finally, the findings will be summarized.

\section{METHOD}

Initial research was carried out by literature review and case studies. The cases are analyzed based on a document study and interviews. The literature review was conducted to learn about the method, explore previous experiences on the method and to develop a theoretical background. Search words used include Best Value Procurement, lean, value, early contractor involvement and ECI. These terms were applied in search engines such as Google Scholar and Oria. In order not to miss important literature, both forward and regular snowballing were used (Wohlin 2014). Forward snowballing was applied to find newer articles, first by searching for core documents such as Kashiwagi (2016), thereby finding newer articles that cite the book.

In this paper, five infrastructure projects were studied to address the three research questions. These five infrastructure projects were selected for the following reasons: they are all mega-projects, the contractor in focus is involved in all of the case projects, and BVP was used as the procurement method in all of the projects. Furthermore, each case project has gone through the clarification phase, enabling them to answer the research questions in this paper. Descriptions of each of these case project are listed in Table 1. 
Table 1: Descriptions of case projects

\begin{tabular}{ccc}
\hline Project name & Cost (USD) & Year \\
\hline E18 Rugtvedt - Dørdal & $210,000,000$ & $2017-2019$ \\
E6 Arnkvern - Moelv & $280,000,000$ & $2017-2020$ \\
E39 Kristiansand west - Mandal east & $530.000,000$ & $2018-2022$ \\
E39 Mandal east - Mandal city & $21,000,000$ & $2020-2022$ \\
E6 Ranheim - Værnes & $59,000,000$ & $2019-2024 / 2025$ \\
\hline
\end{tabular}

The first project (E18 Rugtvedt - Dørdal) was the first project to use BVP in Norway. The client for all projects in this paper is New Roads, a Norwegian government-owned company established to build roads worth \$17.5B USD over the next 20 years (New Roads 2017). The three first projects shown in Error! Reference source not found. are all in the execution phase, while the two last projects have just been signed. All of the projects are located in Norway.

Three semi-structured interviews were conducted according to the method described by Yin (2013). All of the interviewees are from the contractor's perspective. These personnel have had a central role during the procurement phase of the five projects. The interviewees are experienced in the construction industry and are promoters of BVP in their firm.

In the document study, procurement protocols from the five cases were retained from the client, New Roads. Procurement protocols from each of the five projects were studied in order to explore how BVP was practiced and to look at what has changed with the practice over time. These protocols specify each contractor's price and their final scores for the evaluation criteria described in the theoretical framework section. Furthermore, the protocols include descriptions of the grading system and the basis for evaluating price. Data from these protocols were collected and systemized into Excel to retain one document that provides all scores for each project. In addition to procurement protocols, one censured version of the core document from the first project (E18 Rugtvedt - Dørdal) is also used. This document describes the project objectives. The core document for the other project was requested as well, but was not provided.

\section{THEORETICAL BACKGROUND}

\section{LEAN AND BVP}

Lean construction seeks to minimize waste, time and effort in order to maximize value in projects (Koskela et al. 2002). Early contractor involvement (ECI) gives the contractor an opportunity to influence project planning and assist in the creation of buildable solutions (Song et al. 2009). Wondimu et al. (2016) describes several success factors of ECI that, among others, includes involving contractors early enough and managing risk transfer to the contractors.

ECI is one of the measures that can be taken to implement lean in the construction sector. A BVP core principle is to involve the contractor at an early stage in order to help the client identify the risks. BVP can therefore be used as a means to implement Lean in 
the construction sector since it contributes to the maximization of value by involving the contractor early and using contractor expertise to identify the project risk and minimize waste of material, time and effort during the project execution phase (Wondimu et al. 2018).

BVP method has been carried out in 31 states in the U.S. and has spread to other countries worldwide. By 2016, over 1800 projects worth \$6B USD in contracts were completed using BVP (Kashiwagi 2016). The method is based on the philosophy that the contractor is the expert on how to execute the project, relying on contractors to perform their tasks without micromanagement from the client (Van de Rijt and Witteveen 2011). This philosophy encourages transparency and simplicity throughout the project. In the European context, the Norwegian approach on BVP is based on the Dutch version (Högnason et al. 2018).

\section{THE PHASES IN BVP}

The BVP method typically consists of four phases. It is important to understand the four phases used to conduct the BVP method, and to achieve the best value contractor for a specific project (Van de Rijt et al. 2016). The phases are Preparation, Selection, Clarification, and Execution. The phases and their core elements are presented in the following sections.

The Preparation phase is the phase where the client and contractor prepare for the BVP process by education and training in the method (Kashiwagi 2016). In addition, a pre-qualification can be used. Pre-qualification serves to sort potential bidders by requesting financial and legal documents from bidders, but pre-qualification is not mandatory (Kashiwagi 2016). In this first phase, a core document is created. The document contains information regarding the project such as project objectives, scope, and specifications. The criteria to be discussed in the Selection phase should be listed with a weighting for each one (Van de Rijt et al. 2016). Lastly, the budget framework for the project is released. It is not standard practice to disclose information regarding the budget ceiling. However, in the BVP method, this information is useful because it gives the contractors the opportunity to assess whether the project is within their capacity before starting to prepare an offer (Van de Rijt et al. 2016).

The Selection phase aims to find the best value contractor (Van de Rijt et al. 2016). In order to find this contractor, there are several steps that must be conducted. First, the contractors' written offers are evaluated. The written offer covers three criteria: Project Capability, Risk Assessment, and Value Added (Kashiwagi 2016). Each criterion should be at most two pages. The price is provided in a separate document and reviewed last (Kashiwagi and Kashiwagi 2011). The written offers are anonymized in order to maintain an unbiased assessment. After evaluation of the criteria, an interview with key personnel is executed. The interviewees must be persons who directly influence the project from start to finish. These may be the project manager, design manager and/or site manager (Van de Rijt et al. 2016). After the interviews, the price is evaluated. If the price is over the budget framework, the contractor is eliminated from the competition (Kashiwagi 2016). There are several ways to evaluate price. Van de Rijt et al. (2016) propose to transform the score given by the evaluation into the price. Contractors are evaluated 
individually pursuant to fixed scores. Lastly, all data are collected to summarize which contractor best meets the criteria and is selected as the best value contractor.

The Clarification phase begins when one contractor is chosen. During this phase, the contractor should concretize and elaborate on the offer (Van de Rijt et al. 2016). From this point on, the contractor leads the meetings and creates solutions for the project, showing that the offer consists of low risks and meets the project criteria. The client's role shifts to a passive listening role where open and critical questions are asked, leaving the contractor to be the expert. According to Norwegian law, the ban on negotiation must be maintained. Specifically, this ban is broken if there is a change in the characteristics of the offer that were decisive in choosing this contractor, a change in the distribution of risks between client and contractor, or changes outside the boundary of the offer (Andersen et al. 2018). Therefore, the core content of the offer must not be changed. This requirement is due to the fact that it should be clear which contractor delivered the best offer, and by changing the offer itself this distinction is lost. When the Clarification phase ends, the contractor should have a detailed plan for the execution of the project (Van de Rijt et al. 2016). The primary purpose of the Clarification phase is to foresee eventual challenges before the execution begins, making it easier to control these challenges when discovered and addressed early on. If the Clarification phase reveals that the contractor is not able to deliver the terms of their offer, the client can choose to proceed with the contractor that came second (Kashiwagi 2016). When the phase is completed, the contract can be signed and the execution phase can begin.

The Execution phase begins when the contract is signed. The execution should be characterized by openness between the parties. Candid communication and a clear distribution of responsibility are key (Van de Rijt et al. 2016). According to the BVP philosophy, the contractor remains the expert. This expectation results in minimal disturbance and micromanagement from the client. To keep track of progress, the contractor delivers weekly risk reports to the client (Kashiwagi 2016). In this weekly report, the contractor lists risks that influence the progress along with the impact on scope, cost and quality. In addition, the reports contain strategies for risk management, which demonstrates to the client that the contractor has the project under control. Provided that weekly reports are done correctly, these reports should be sufficient for the client to maintain oversight of the project (Kashiwagi 2016).

\section{BVP IN NORWAY}

The BVP method was introduced in Norway in 2016 by the Directory of Procurement and ICT, called Difi (Direktoratet for forvaltning og IKT). Difi personnel arranged testing of the method on more than ten pilot projects. They also contributed to judicial clarification on the method and arranged pilot seminars and courses. Their role is to document and evaluate results from these pilot projects that are expected to eventually result in best-practice guidance on BVP in Norway. The goal of the pilot projects is to determine whether the BVP method creates higher value, increases effectivity and reduces costs and use of resources (Difi 2016).

New Roads is a government-owned company that aspires to build roads worth $\$ 17.5 \mathrm{~B}$ USD in Norway over the next 20 years (New Roads 2017). The company uses both BVP 
and Early Contractor Involvement (ECI) in their procurements. For all five of the projects in this paper, New Roads is the client.

\section{RESULTS AND DISCUSSION}

In this paper, we set out to address how the BVP was implemented in practice, what experience the contractors had and how the method can be improved in the future.

\section{BVP IN PRACTICE}

The implementation of BVP in Norway has its basis in the Dutch method as a result of the Dutch adopting the BVP method from the U.S. and altering it to comply with Dutch and EU legislation (Van de Rijt and Santema 2012). BVP in Norway aligns closely with the theoretical approach set by the Dutch.

In every project, we studied, all four phases of the method were used. Prequalification was used to sort out the bidders before starting each project's competition. The implementation of BVP in Norway aligns with how Van de Rijt et al. (2016) propose it be conducted.

Three of the five projects are in the execution phase to date, so it is not known what effects the BVP process will have on the final outcomes. All three projects have moved to a standard Norwegian contract designated NS 8407 in the execution phase. Kashiwagi (2016) states that the only report needed during the execution phase is the weekly risk reports. Regardless of this expectation, the interviewees reported that the weekly report was added to other reports required by the contract (NS 8407). The additional reporting results in using extra resources and does not align with the BVP philosophy where a key factor is less management from the client. This understanding is supported by Narmo et al. (2018), who stated that the contract NS 8407 does not support use of the weekly risk report alone. This result indicates that BVP is being used only in the procurement phase.

\section{EXPERIENCES WITH BVP}

In general, the view of BVP has been positive from a contractor's point of view. The primary emphasis in the interviews was on the challenges in following the method. In Table 2 a summary of the pros and cons of BVP is provided.

Table 2: Pros and cons with BVP

\begin{tabular}{cc}
\hline Pros & Cons \\
\hline $\begin{array}{c}\text { Improves the efficiency in } \\
\text { producing an offer }\end{array}$ & $\begin{array}{c}\text { Learning the method is time } \\
\text { consuming }\end{array}$ \\
$\begin{array}{c}\text { Reduces costs and resources in } \\
\text { producing an offer }\end{array}$ & $\begin{array}{c}\text { Vagueness regarding evaluation } \\
\text { of price }\end{array}$ \\
Able to influence the project early & $\begin{array}{c}\text { Detailed management from client } \\
\text { in execution phase }\end{array}$ \\
\hline
\end{tabular}

The interviewees were clear in their opinion that BVP improves efficiency and reduces the costs and use of resources involved in producing an offer. Nevertheless, 
learning how the BVP process is carried out is time consuming but well worth the time according to the interviewees.

The opportunity to influence the project at an early stage gave contractor personnel a feeling of being the expert and allowed them to develop buildable solutions.

The contractor experienced a high amount of inspection and control from the client during the execution phase. The interviewees stated that "the client has an extreme amount of detail management in this phase - we do not see any of the BVP philosophy, on the contrary, this regime means we need more resources and costs to follow up on their demands."

Additionally, interviewees felt that the evaluation regarding the price criterion was not consistent in each project, so we investigated and describe the evaluation of price in detail in the following sections.

\section{Evaluation of price}

Even though the general view of the BVP method was positive, some elements of the evaluation of price criteria were found to be a challenge by the contractors. Results from procurement protocols and interviews are presented and discussed below to highlight these challenges.

The procurement protocols show how the prices were evaluated. Van de Rijt et al. (2016) proposed a method of evaluating price that involves converting points into price. A different method was used in these five projects to evaluate price. The evaluation was based on two different formulas, shown in Table 3.

Table 3: Two methods of evaluating price

\begin{tabular}{cc}
\hline Name & Formula used \\
\hline $\mathrm{A}$ & $\frac{\text { Budget frame }+ \text { maintenance }- \text { actual price }}{\text { Budget frame }+ \text { mainenence }- \text { lowest price }} \times 100$ \\
$\mathrm{~B}$ & $\frac{\text { Lowest price }}{\text { Actual price }} \times 100$ \\
\hline
\end{tabular}

After using formula A in the first three projects, a shift to formula B was implemented for project E19 Mandal east - Mandal city. This change is shown in Table 4. One of the interviewees described the following regarding formula A: "I thought the formula was weird, and our BVP expert from The Netherlands also thought so. It was implied that the intention behind the formula was to motivate to give the lowest possible price. You should offer a very low price in order to gain many points." 
Table 4: Overview of which method was used in each project

\begin{tabular}{cc}
\hline Project name & Formula used \\
\hline E18 Rugtvedt - Dørdal & A \\
E6 Arnkvern - Moelv & A \\
E39 Kristiansand - Mandal east & A \\
E39 Mandal east - Mandal city & B \\
E6 Ranheim - Værnes & B
\end{tabular}

In order to visualize how formula $\mathrm{A}$ and $\mathrm{B}$ differed with regard to price evaluation, data from three projects are used. The results can be seen in Table 5.

Table 5: Weighted scores given with formula A and B

\begin{tabular}{ccccc}
\hline Project name & Offer & Formula A & Formula B & Difference \\
\hline E18 Rugtvedt - Dørdal & Price 1 & 25 & 25 & $\mathbf{0}$ \\
(Max score: 25) & Price 2 & 7 & 19.4 & $\mathbf{1 2 . 4}$ \\
& Price 3 & 0 & 17.9 & $\mathbf{1 7 . 9}$ \\
E6 Arnkvern - Moelv & Price 1 & 25 & 25 & $\mathbf{0}$ \\
(Max score: 25) & Price 2 & 16 & 23.9 & $\mathbf{7 . 9}$ \\
& Price 3 & 10 & 24.3 & $\mathbf{1 4 . 3}$ \\
E39 Kristiansand - Mandal & Price 1 & 25 & 25 & $\mathbf{0}$ \\
east & Price 2 & 18.69 & 24.87 & $\mathbf{6 . 1 8}$ \\
(Max score: 25) & & & & \\
\hline
\end{tabular}

As Table 5 shows, the two formulas produce different scores for each price offer. The high score does not differ because the lowest price automatically gets the full score. In these projects, full score in price equals 25 points. Nevertheless, the other offers differ in scores from formula A to B; e.g., one of the offers has a difference of 17.9 points. All of the scores were increased by using formula B. The smallest increment was 6.18 points. Therefore, there is no doubt that by using formula A, the scores are lower and the difference between offers is greater. This discrepancy aligns with comments from the interviewee who stated that pricing very low would result in many points with these projects. The worst-case scenario would be losing the project due to a method that is unfair. Formula B is also used to rank offers for the other four criteria, which was used throughout all of the projects.

\section{A shift in the pricing model}

As shown in Table 4, a shift from using formula A to B was first carried out in the project E39 Mandal east - Mandal city. In this project, a new method for pricing was also introduced because that the contractors were responsible for developing the project by producing the zoning plan. This new method is based on two factors that together would represent the contractor's price. First, the contractor sets a man-hour rate and then multiplies this rate with the given number of hours used to develop the project. Second, 
the contractor sets a profit percentage that is multiplied with the budget ceiling. This result represents the payment during the execution phase. The two prices are then added, and together they make the contractor's price. This method of pricing was also used in the last project, E6 Ranheim - Varnes, where the contractor also developed the zoning plan. In the previous projects, the fixed sum pricing model was used.

The interviewees were positive about this updated pricing model and thought that formula B seemed to be a fair way to rank the offers. Formula B did not calculate their offers against the budget ceiling. It made the differences in price between the offers more realistic with regard to achieved points. It is unknown if there is a link between the new pricing model and the evaluation of the price.

\section{BVP IN THE FUTURE}

There are several findings in this paper that could be implemented to improve BVP in Norway. The following suggestions are developed from the cons found in Table 2.

The evaluation of price: Two different formulas were used to evaluate price. One method was criticized by the contractors because it motivated contractors to price very low in order to gain many points. The second method (formula B) was considered more reasonable and should be used in future projects.

The execution phase: In practice, the weekly reports and mandatory reports due to contract NS 8407 increase the need for resources and cost in the projects. One interviewee stated, "the client has many controls and inspections. It is far more than we are used to in previous contracts." This practice directly contradicts the BVP philosophy. A solution could be to move forward with the weekly risk report and discard the other reports. This would require a change in contract.

Learning the method is time-consuming: Learning the BVP method takes time. The interviewees stated that the first BVP offer was time-consuming and that they used a lot of recourses developing the 6 pages required. The contractor also hired a BVP expert from The Netherlands to minimize the need for education and benefit from the expertise. Nevertheless, the second offer proved to require fewer resources because they had already gone through the process before. It gets easier every time.

\section{CONCLUSION}

This paper set to answer 1) How BVP was implemented in practice 2) what the contractors' experiences are with BVP method and 3) how the method can be improved in the future.

\section{1) How was BVP implemented in practice?}

All of the case projects followed the four phases of the method described by the founder of the method. Pre-qualification was also used in all of the case projects in order to sort the bidders before starting the competition. In the execution phase, the contract NS 8407 has taken over for the execution phase. None of the case projects have finished to this date.

\section{2) What are the contractors' experiences with the BVP method?}


The contractors' experiences are mostly positive with regard to the method. However, they were doubtful regarding how the evaluation of price was used. This paper has shown how two different formulas (A and B) were used to evaluate price. Examples show how the end score differed when shifting from formula A to B. This difference could have awarded the project to a different contractor, proving the interviewee's point regarding getting more points by lowering the price when formula A was used.

In the execution phase, all case projects were subject to a NS 8407 contract in addition to the weekly reports. This implementation results in an increased need for recourses and greater costs in this phase, and this does not align with the BVP philosophy.

The interviewees expressed confidence that the implementation of the BVP method will improve with experience and will spread in the Norwegian construction industry.

\section{3) How can the method be improved in the future?}

In order to facilitate the implementation of Lean in future projects by using BVP, the practise of the method should be improved. Improvement measures include implementing BVP philosophy and methods during the execution phase, minimizing micromanagement of the contractor and having a transparent evaluation method. These measures could reduce the probability of ending up in conflict. Conflict is one of the major sources of waste of time and resources. By improving the practice of BVP, it may be possible to improve lean practice. Formula B should be used to evaluate price in the future.

In the future, it is recommended that interviews with New Roads and insight into core documents be done to enlighten some of the questions raised in this paper. Also, the effects of BVP should be studied during and after the execution phase. Finally, more studies about the evaluation of price and criteria should be conducted for comparison with this paper.

\section{REFERENCES}

Andersen, A. T., Arendt, T., and Ramstad, J. (2018). "Legal issues due to Best Value Procurement (BVP)."

Brekkhus, A. (2017). "The construction industry has never had such a large share of GDP." <http://www.bygg.no/article/1310113>. (11.15, 2018).

Difi (2016). "Pilot of BVP in Norway." <https://www.anskaffelser.no/hva-skal-dukjope/bygg-anlegg-og-eiendom-bae/best-value-procurement-bvpprestasjonsinnkjop/pilotering-av-bvp-i-norge> . (09.01, 2019).

Focus Economics (2018). "Economic Growth (GDP, annual variation in \%)." <https://www.focus-economics.com/economic-indicator/gdp >.

Högnason, G. O., Wondimu, P. A., and Lædre, O. (2018). "Best Value Procurement - The First Experience from Norway." Creative Construction Conference 2018, Ljublijana, Slovenia, 329-336.

Kashiwagi, D. T. (2016). 2016 Best Value Approach, KSM.

Kashiwagi, D. T., and Kashiwagi, J. (2011). "Case Study: Performance Information Procurement Systen (PIPS) in the Netherlands." Malaysian Construction Research Journal, 8(1).

Kashiwagi, D. T., Kashiwagi, J., Smithwick, J., and Kashiwagi, I. (2012). "Changing the paradigm." International Public Procurement Conference, 1074-1095. 
Koskela, L., Howell, G., Ballard, G., and Tommelein, I. (2002). "The foundations of lean construction." Design and construction: Building in value, 211-226.

Narmo, M., Wondimu, P. A., and Lædre, O. (2018). "Best Value Procurement (BVP) in a Mega Infrastructure project." Group for Lean Construction (IGLC 26)Chennai, India, 23-33.

New Roads (2017). "Our procurements methods." <https://www.nyeveier.no/om-nyeveier/slik-gjoer-vi-vaare-anskaffelser/>. (20.09, 2018).

Song, L., Mohamed, Y., and AbouRizk, S. M. (2009). "Early Contractor Involvement in Design and Its Impact on Construction Schedule Performance." Journal of Management in Engineering, 12-20.

Van de Rijt, J., and Santema, S. C. (2012). "The Best Value Approach in the Netherlands: A reflection on Past, Present and Future." Journal for the Advanced of Performance Information and Value, 4(2), 14.

Van de Rijt, J., Santema, S. C., and Soilammi, A. (2016). Best Value Procurement Prestasjonsinnkjфp, RIF, translated from Dutch.

Van de Rijt, J., and Witteveen, W. (2011). "Contractor selection using BVP in the construction industry. Case studies at the Dutch Ministry of Infrastructure." IPSERA 2011Maastricht, 7.

Wohlin, C. (2014). "Guidelines for Snowballing in Systematic Literature Studies and a Replication in Software Engineering." Proceedings for the 18th International Conference on Evaluation and Assessment in Software Engineering, ACM, London, England, United Kingdom, 1-10.

Wondimu, P. A., Hailemichael, E., Hosseini, A., Lohne, J., Torp, O., and Lædre, O. (2016). "Success factors for early contractor involvement (ECI) in public infrastructure projects." SBE16; Build Green and Renovate DeepTallinn and Helsinki, 845-854.

Wondimu, P. A., Klakegg, O. J., Lædre, O., and Ballard, G. (2018). "A comparison of competitive dialogue and best value procurement." Proc. 26th Annual Conference of the International Group for Lean Construction (IGLC)Chennai, India, 13-22.

Yin, R. K. (2013). Case study research: Design and methods, Sage publications. 
Lesjø ES, Lædre O., and Wondimu, P 